\title{
Various Effects of Particle Movement in a Single Phase Uncoated Encapsulated GIS with Various Gas Mixtures
}

\author{
P Srinath Rajesh \\ Adams Engineering College \\ Paloncha, India
}

\author{
J Amarnath, Ph.D \\ Professor, JNTUHCEH \\ Hyderabad, India
}

\begin{abstract}
$\mathrm{SF}_{6}$ gas compressed in metal encapsulation has lessened the size of transmission and distributed substation as well as reliability is enhanced considerably over conventional substations. Metal encapsulated gas insulated substation (GIS).Basically consists of enclosure, insulators to support conductor which is crammed with $\mathrm{SF}_{6}$ gas. Since $\mathrm{SF}_{6}$ is a green house gas leads to global warming, one alternate arrangement to $\mathrm{SF}_{6}$ is to use gas mixture .This gas mixture gives matching chemical and physical properties as $\mathrm{SF}_{6}$. In a GIS the withstand capability of voltage level depends on field perturbations which occurs due to imperfections on the surface and by contaminated particles which are conducting. The conducting particles lifts up and migrate to various portions in between inner conductor and outer enclosure which leads to breakdown at voltage levels below $\mathrm{SF}_{6}$ gas insulation characteristics. In this paper, using the equation of particle motion in an electric field, simulation of particle movement is carried out for various gas mixtures such as $\mathrm{SF}_{6} / \mathrm{Air}, \mathrm{SF}_{6} / \mathrm{Ar}, \mathrm{SF}_{6} / \mathrm{Kr}, \mathrm{SF}_{6} / \mathrm{CO}_{2}$ and $\mathrm{SF} 6 / \mathrm{N}_{2}$ of various proportions. $\mathrm{Cu}$ and $\mathrm{Al}$ are considered as metallic particles for the study to examined and presented.
\end{abstract}

\section{Keywords}

Encapsulated GIS, global warming, particle contamination, gas mixtures, particle movement.

\section{INTRODUCTION}

The most commonly used insulating gas in electrical system is SF6 gas till date [1]. Encapsulated Gas insulated substations are most widely used in the modern electrical power systems for distribution and transmission of electrical power. The entire substation equipments such as disconnectors,busbars,current transformer, potential transformers, circuit breakers, power transformers, etc are insulated with sf6[2]. The power industry uses approximately $80 \%$ of the SF6 produced worldwide and rest of the sf6 production is used in various industries related to magnesium,aluminium,semiconductors ect,demand for sf6 is raising day by day. Accumulation of sf6 is serious concern since sf6 is a 'greenhouse' gas and it leads to global warming [3] and it is estimated that global warming potential of SF6 is 25,000 times greater than that of $\mathrm{CO} 2$. The possible solution to this problem is to use gas mixtures such as Air/ $\mathrm{Ar} / \mathrm{Kr} /$ $\mathrm{CO} 2 / \mathrm{N} 2$ in sf6.

The dielectric strength of this gas mixtures are very high, but voltage with stand voltage reduces drastically within the Gas Insulated substation due to metallic particles present in the system creates localized electrical stress. These particles are originated during the manufacturing process, assembling process or from mechanical vibrations or from circuit breakers moving parts. The shape of these particles may be of spherical, wire like (filamentary) or fine dust. When these particles are subjected to uniform field of alternating current at certain voltage. As the voltage enhances above certain level, the particle undergo bouncing state due to alternating current reaches a height depends on the applied voltage. As the voltage increases further, the bouncing height increases which leads to break down .so, metallic free wire particles are more dangerous and harmful and more pronounced effects takes place at higher voltages [4].

The reliability of compressed Gas Insulated Substation can be improved by eliminating the effects of these metal particles and one of the methods suggested is using adhesive coatings on GIB electrodes. The movement of particle in GIS is a serious concern

In this paper,work related with the particle movement of wire like conducting particle in single phase encapsulated Gas Insulated Substation using various gas mixtures is been carried out with different proportions. The particle movement in enclosure is determined using analytical method in conjunction with motion equation. The simulation work specifically reports the acquired charge of the particle, the force exerted by the electrical field on the charged particle, force due to drag and particle movement random behavior.

\section{MATHEMATICAL MODELING}

The typical arrangement of single phase encapsulated gas insulated substation is shown in the figure 1.The enclosure is filled with sf6 gas mixture at high pressure. In the enclosure the metallic particle is said to be at rest, under the bus bar, the particle tends to lift up and travel if sufficiently large enough voltage is applied. The particle travels in the direction of field after getting sufficient charge overcoming drag force and own weight force.

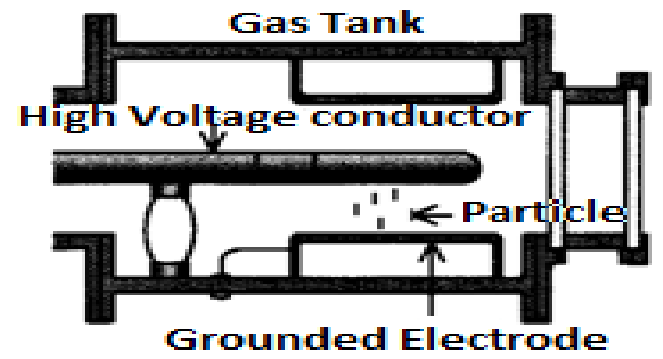

Fig. 1 Typical 1-phase encapsulated GIS

The particle macroscopic field, Reynolds's number, viscosity of Sf6 gas mixture and restitution coefficient is considered for simulation. A new charge is acquired by the particle during return flight which is dependent on instantaneous electric 
field. Many Authors [3-5] suggested solutions for the motion equation of various particle of spherical and wire type in nature in a encapsulated Gas Insulated Substation is depent on the drag force, electrostatic force and gravitational force. The motion equation can written as

$$
F e-m g-F d=\frac{\mathrm{d}^{2} \mathrm{y}}{\mathrm{dt}^{2}}
$$

This equation results in second order non-linear differential equation, using Runge-Kutta 4th order method is used to solve this equation.

\section{SIMULATION OF ELECTRIC FIELD IN GAS INSULATED BUSDUCT WITH GAS MIXTURES}

The viscosity of the gas mixture is very important in GIS to the drag force and the viscosity of two gasses can be calculated from the equation

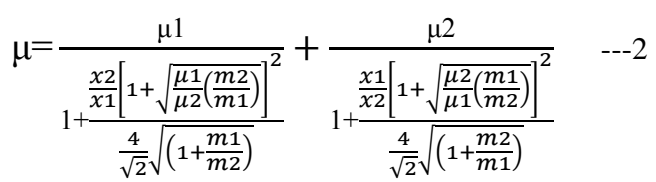

Where $x_{1}, x_{2}, \mathrm{~m}_{1}, \mathrm{~m}_{2}$ and $\mu_{1}, \mu_{2}$ are gas proportions, molecular weights and gas viscosities in that order correspondingly. Subsequent to this equation value of Reynolds number is calculated to substitute in motion equation. The Gas Insulated Busduct conductors and Enclosure radii are $27.5 \mathrm{~mm}$ and $76 \mathrm{~mm}$ respectively. $\mathrm{Al} / \mathrm{Cu}$ metallic Particle length $=12 \mathrm{~mm}$, radius $=0.25 \mathrm{~mm}$ and GIS pressure is $0.4 \mathrm{MPa}$, Restitution Coefficient is 0.9. Considering the above equations c program was developed and used for all simulation studies.

\section{RESULTS AND DISCUSSIONS}

From Table I it is observed that for voltage of $75 \mathrm{KV}$ for pure SF6 i.e. $0 \%$ concentration of Gas Mixtures (Ar/Kr/Air/ CO2 /N2) maximum movement of $1.771632 \mathrm{~mm}$ recorded for Copper particle and in case of $30 \%$ gas mixture $(\mathrm{Ar} / \mathrm{Kr} / \mathrm{Air} /$ $\mathrm{CO} 2 / \mathrm{N} 2)$ and $70 \%$ SF6 mixture the corresponding values are $1.702797 \mathrm{~mm}, 1.765492 \mathrm{~mm}, 1.762953 \mathrm{~mm}, 1.750118 \mathrm{~mm}$, $1.763348 \mathrm{~mm}$ respectively. It is observed that as the percentage of gas mixture changes the maximum radial movement also changes. From Table $\mathrm{I}$ it is observed that, radial movement is less for $60 \%$ of Ar in SF6 and Ar gas mixture, less for $60 \%$ of $\mathrm{Kr}$ in SF6 and $\mathrm{Kr}$ gas mixture, radial movement is less for $60 \%$ of Air in SF6 and Air gas mixture, radial movement is less for $100 \%$ of $\mathrm{CO} 2$ in SF6 and $\mathrm{Co} 2$ gas mixture, radial movement is less for $30 \%$ of $\mathrm{N} 2$ in SF6 and N2 gas mixture. Figures 1-5 shows the particle movement of
Aluminum particle of wire type with SF6 Gas Mixtures for 75 $\mathrm{KV}$ in a Single phase encapsulated GIS for a proportion of 70\% SF6 and 30\% Gas Mixture.Similarly From Table II it is observed that for voltage of $75 \mathrm{KV}$ for pure SF6 i.e. 0\% concentration of Gas Mixtures (Ar/Kr/Air/ CO2 /N2) maximum movement of $9.327675 \mathrm{~mm}$ recorded for Aluminum particle and in case of $30 \%$ gas mixture $(\mathrm{Ar} / \mathrm{Kr} / \mathrm{Air} / \mathrm{CO} 2 / \mathrm{N} 2)$ and $70 \%$ SF6 mixture the corresponding values are $9.027155 \mathrm{~mm}, \quad 9.119467 \mathrm{~mm}, \quad 9.128488 \mathrm{~mm}, \quad 9.132974$, $9.043084 \mathrm{~mm}$ respectively. From Table II it is observed that, radial movement is less for $60 \%$ of $\mathrm{Ar}$ in SF6 and $\mathrm{Ar}$ gas mixture, less for $60 \%$ of $\mathrm{Kr}$ in SF6 and $\mathrm{Kr}$ gas mixture, radial movement is less for $60 \%$ of Air in SF6 and Air gas mixture, radial movement is less for $100 \%$ of $\mathrm{CO} 2$ in SF6 and $\mathrm{Co} 2$ gas mixture, radial movement is less for $30 \%$ of $\mathrm{N} 2$ in SF6 and $\mathrm{N} 2$ gas mixture. Figures 1-5 shows the particle movement of Copper particle of wire type with SF6 Gas Mixtures for 75 $\mathrm{KV}$ in a Single phase encapsulated GIS for a proportion of $70 \%$ SF6 and 30\% Gas Mixture.

Table I: Variation in particle movement of Aluminum particle of wire type with $\mathrm{SF}_{6}$ and Gas Mixtures of various proportions for $75 \mathrm{KV}$ in a Single phase encapsulated GIS

\begin{tabular}{|c|c|c|c|c|}
\hline \multirow{2}{*}{$\begin{array}{c}\text { Mixtur } \\
\mathrm{e}\end{array}$} & \multicolumn{4}{|c|}{ Maximum Movement (mm) for 75 KV } \\
\cline { 2 - 5 } & 0 & 30 & 60 & 100 \\
\cline { 2 - 5 } & \multicolumn{4}{|c|}{ (Ar/Kr/Air/ CO2 /N2) } \\
\hline $\mathrm{Ar}$ & 9.327675 & 9.027155 & 8.988458 & 9.397079 \\
\hline $\mathrm{Kr}$ & 9.327675 & 9.119467 & 9.097766 & 9.134595 \\
\hline $\mathrm{Air}$ & 9.327675 & 9.128488 & 9.035624 & 9.134826 \\
\hline $\mathrm{Co} 2$ & 9.327675 & 9.132974 & 9.094575 & 8.890908 \\
\hline $\mathrm{N} 2$ & 9.327675 & 9.043084 & 9.440674 & 9.012948 \\
\hline
\end{tabular}

Table II: Variation in particle movement of Copper particle of wire type with $\mathrm{SF}_{6}$ and Gas Mixtures of various proportions for $75 \mathrm{KV}$ in a Single phase encapsulated GIS

\begin{tabular}{|c|c|c|c|c|}
\multirow{2}{*}{$\begin{array}{c}\text { Gas } \\
\text { Mixture }\end{array}$} & \multicolumn{4}{|c|}{ Maximum Movement $(\mathrm{mm})$ for $75 \mathrm{KV}$} \\
\cline { 2 - 5 } & $\mathrm{Ar} / \mathrm{Kr} / \mathrm{Air} / \mathrm{CO}_{2} / \mathrm{N}_{2}$ ) \\
\cline { 2 - 5 } & 0 & 30 & 60 & 100 \\
\hline $\mathrm{Ar}$ & 1.771632 & 1.702797 & 1.768217 & 1.716991 \\
\hline $\mathrm{Kr}$ & 1.771632 & 1.765492 & 1.762893 & 1.75722 \\
\hline $\mathrm{Air}$ & 1.771632 & 1.762953 & 1.771599 & 1.76201 \\
\hline $\mathrm{Co}_{2}$ & 1.771632 & 1.750118 & 1.764246 & 1.762482 \\
\hline $\mathrm{N}_{2}$ & 1.771632 & 1.763348 & 1.745147 & 1.771889 \\
\hline
\end{tabular}

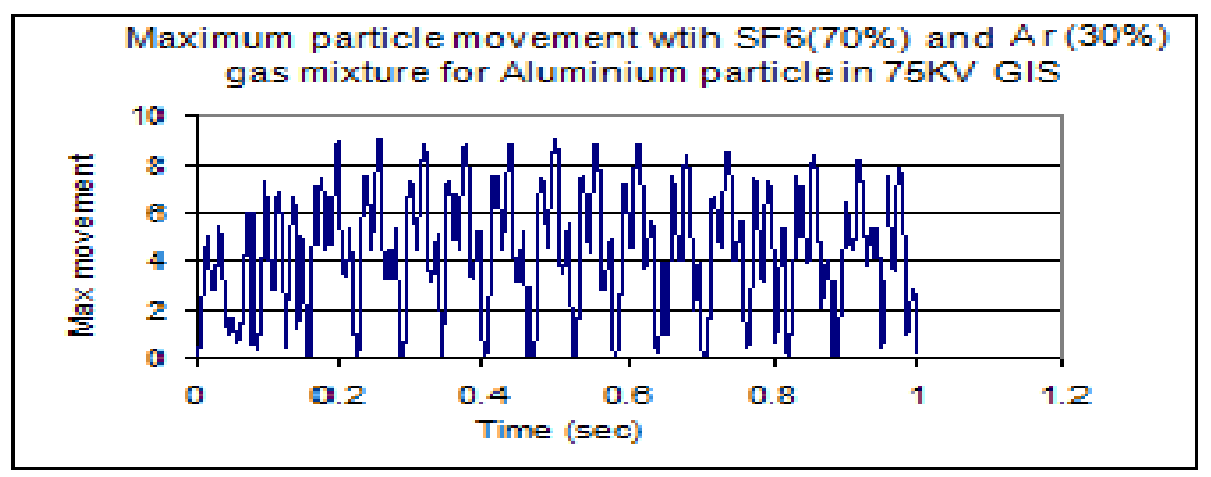

Figure 1 


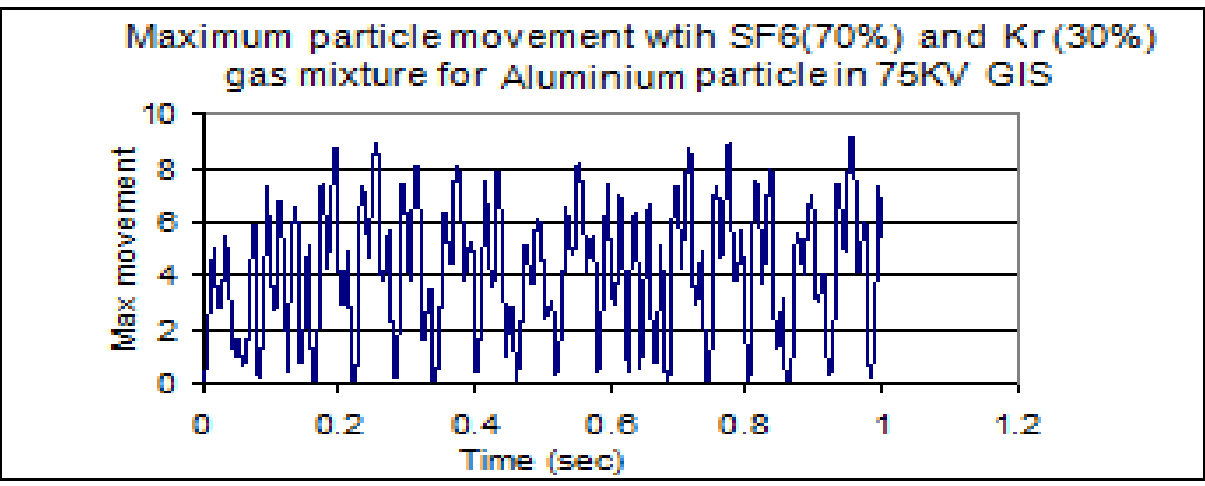

Figure 2

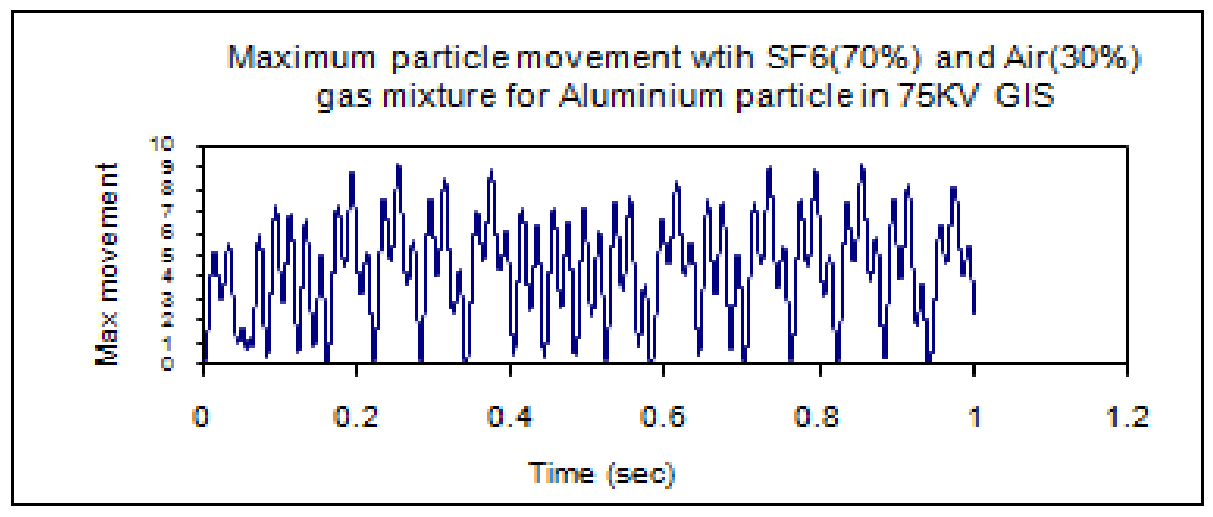

Figure 3

Maximum particle movement wtih $\mathrm{SF} 6(70 \%)$ and $\mathrm{CO}_{2}(30 \%)$ gas mixture for Aluminium particle in $75 \mathrm{KV}$ GIS

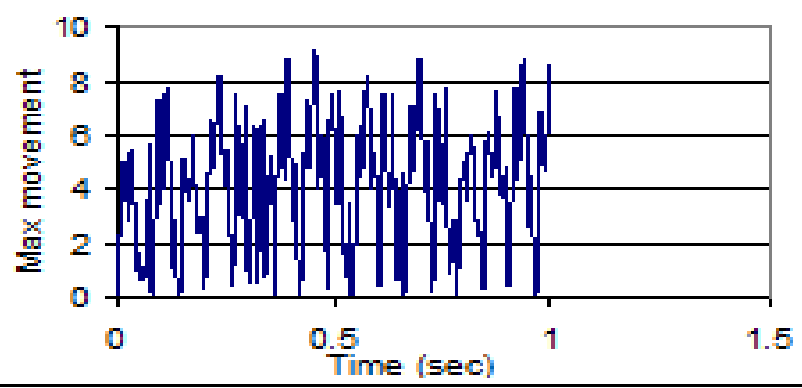

Figure 4

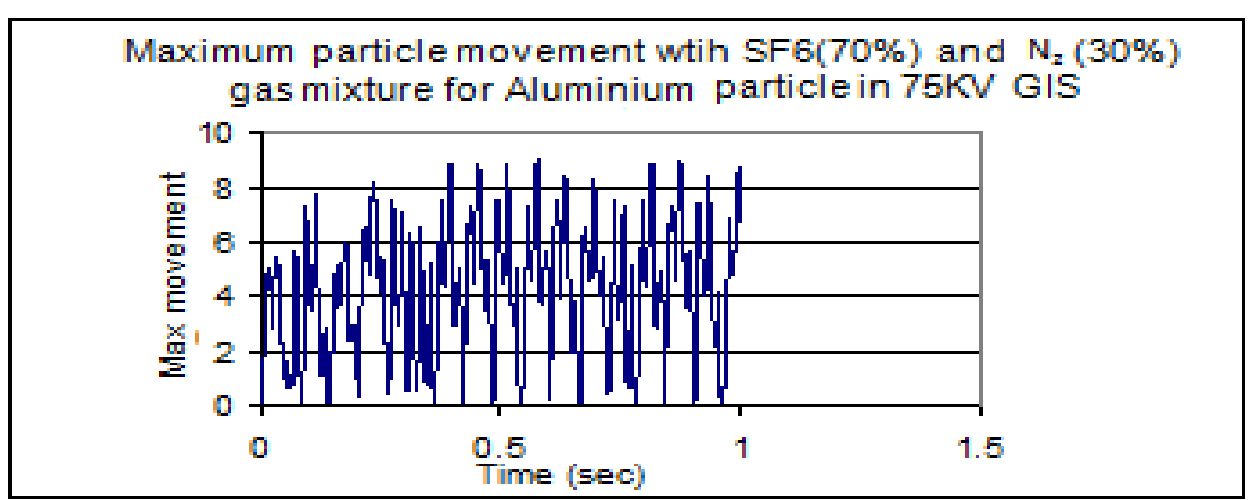

Figure 5 


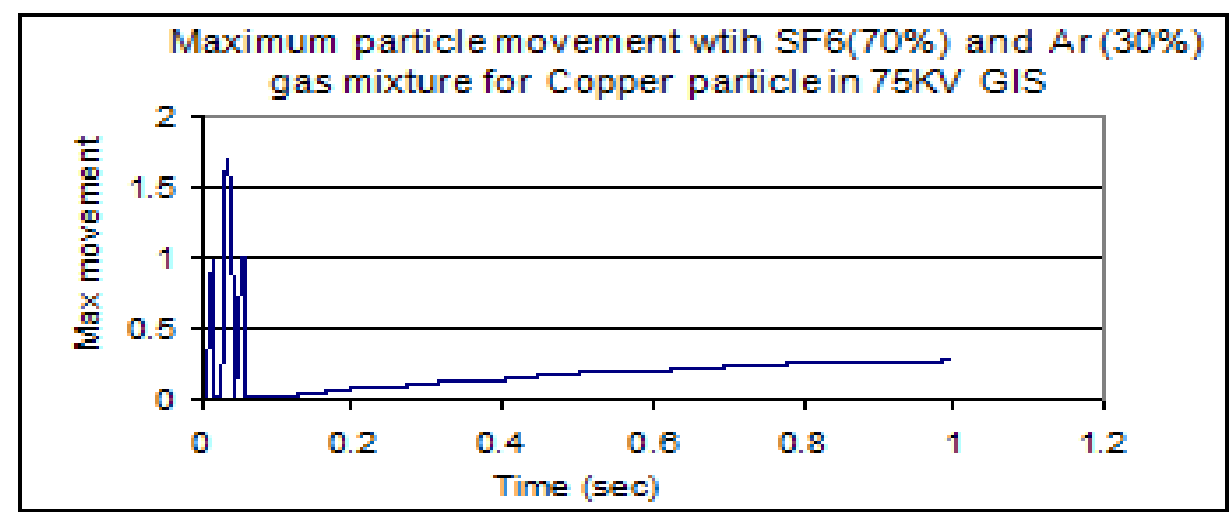

Figure 6

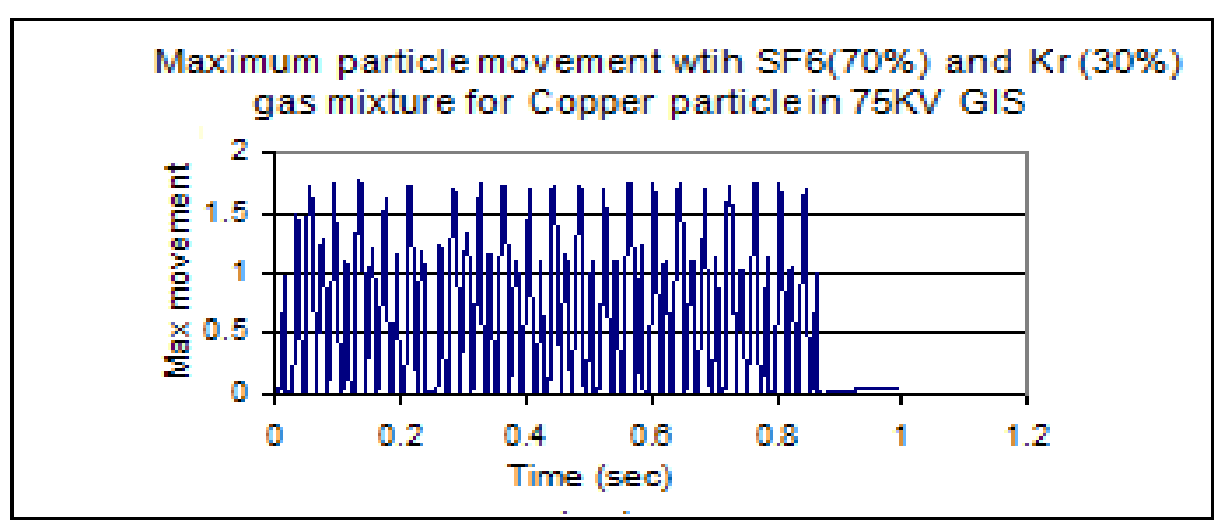

Figure 7

Maximum particle movement wtih SF6(70\%) and Air(30\%) gas mixture for Copper particle in $75 \mathrm{KV}$ GIS

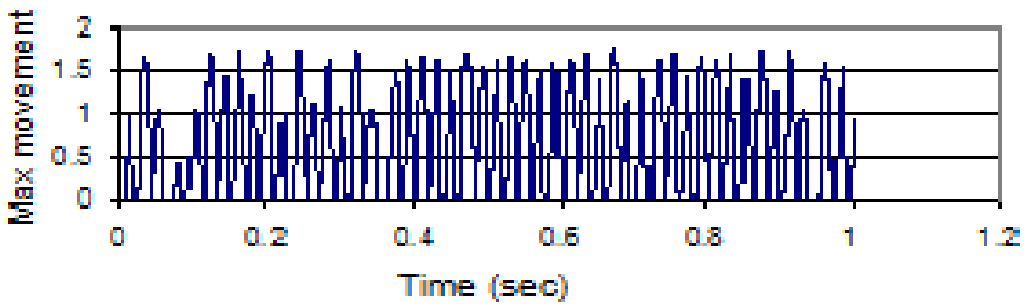

Figure 8

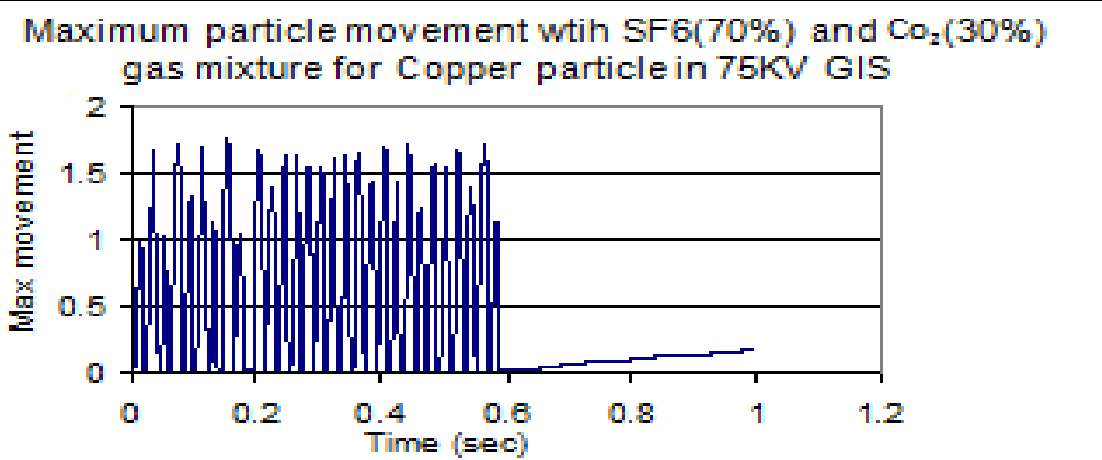

Figure 9 


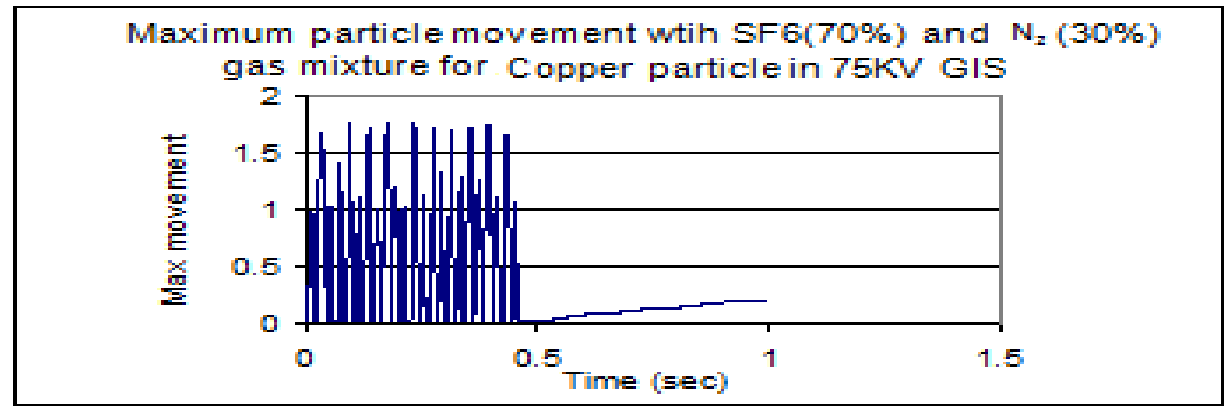

Figure 10

\section{CONCLUSION}

In this paper with $\mathrm{SF}_{6}$ gas and other gas mixtures the movements of wire like particles are modeled and simulated. The simulated results are examined and presented. From the findings it is observed that the radial movement of the particle is least for majority of gas mixtures when $40 \% \mathrm{SF}_{6}$ and $60 \%$ Gas mixture is used in single phase uncoated encapsulated GIS. Consequently encapsulated GIS have better reliability at this proportion. Since Accumulation of sf6 is serious concern since sf6 is a 'greenhouse' gas and it leads to global warming this kind of encapsulated GIS using various gas mixtures reduces the usage if $\mathrm{SF}_{6}$ to higher extent. Further this study can be carried out on the particle behavior of various gas mixtures with coating the inner surface with dielectric material of enclosure

\section{ACKNOWLEDGMENTS}

The authors are gratified to authorities of JNTUH, Hyderabad, and Adams Engineering College, Paloncha, India.

\section{REFERENCES}

[1] W.T Shugg, Handbook of Electrical and Electronic Insulating Materials, Second Edition, IEEE Press, NY, pp. 433-452, 1995.

[2] D.Kopejkova, T.Molony, S.Kobayashi and I.M.Welch,"A Twenty Five Year Review of Experience with Sf6 Gas Insulated Substations", CIGRE, paper 231091, 1992.
[3] E. Cook, "Lifetime Commitments: Why Climate PolicyMakers Can't Afford To Overlook Fully-Fluorinated Compounds", World Resources Institute, Washington, Dc, Feburary, 1995.

[4] H. Anis, K.D. Srivastava "Free conducting particles in compressed gas insulation"; IEEE Trans. on electrical insulation, Vol. EI-16, pp. 327-338, Aug.1995.

[5] J. Amarnath, B.P. Singh, C. Radhakrishna and S. Kamakshaiah, "Determination of Metallic particle trajectory in a Gas insulated Busduct predicted by Monte-Carlo technique," CEIDP, October 17-21, 1999, Texas, Austin, USA.

[6] J.M.K. MacAlpine, and A.H. Cookson, "Impulse breakdown of compressed gases between dielectriccovered electrodes", Proc.IEE,117, pp.646-652, 1970

[7] D. J. Chee-Hing and Srivastava K.D., "Insulation performance of dielectric - coated electrodes in SF6 gas", IEEE Trans on Elect. Insulation. Vol. EI -10, pp 119-124, 1975

[8] A. E. Vlastos, S. Rusck, "The influence of a thin electrode coating on the AC breakdown of SF6", IEE Fourth Intern. Conf. on Gas Discharges, London, UK, 1976, pp. 59-62. 